\title{
Seasonal fish species composition, catch rate and catch value in the small scale fishery of a tropical monsoon estuary along southwest coast of India
}

Authors Info

G.B. Sreekanth', N. Manju Lekshmi', S.K. Chakraborty', A.K. Jaiswar ${ }^{2}$ and N.P. Singh ${ }^{1}$

${ }^{1}$ ICAR-Central Coastal Agricultural Research Institute, Old Goa, Goa-403 402, India

${ }^{2}$ ICAR-Central Institute of Fisheries Education, Mumbai-400 061, India

${ }^{*}$ Corresponding Author Email : gbsree@gmail.com

Key words

Catch rates,

Catch value, Estuary,

Fisheries management,

Zuari estuary

Publication Info

Paper received : 05.12 .2015

Revised received : 04.06.2016

Re-revised received: 03.07 .2016

Accepted: 16.07 .2016

\section{Abstract}

Aim : The assessment of tropical coastal ecosystems involving small scale fisheries is a pre-requisite for fisheries management. With a total area of $39.9 \mathrm{~km}^{2}$, Zuari estuary in Goa is one of the major estuaries located along the southwest coast of India and it holds a small scale fishery for the tribal fishermen residing along the coastal stretch of the estuary. The main objective of the study was to analyse seasonal patterns in fish species composition, catch rates and catch value in the small scale fishery of Zuari

Methodology : Insitu fishing operations were carried out on monthly basis in Zuari estuary from September, 2013 to August, 2015 and fish and shellfish fauna collected during the study were identified to the family, genus and species levels. The data collected on the species assemblages were used to study the seasonal patterns in fish assemblages, catch rates (CPUE) and catch value (VPUE) in Zuari estuary.

Results : A total of 68,715 organisms weighing $13980.4 \mathrm{~kg}$ were caught in 288 fishing operations from 2013 to 2015 in Zuari estuary. Two hundred and thirteen species from 74 families were identified and 30 species contributed about $60-70 \%$ of the catch. Escualosa thoracata, Sardinella longiceps, Mugil cephalus, Tenualosa toli, Fenneropenaues indicus, Portunus pelagicus, Thryssa malabarica, Rastrelliger kanagurta, Nematalosa nasus and Metapenaeus dobsonii were the dominant species on the basis of relative importance index (RII). There were significant seasonal variations in abundance, species composition, catch rate (CPUE) and catch value (VPUE). There was seasonality in fish species composition and maximum species diversity was observed during pre-monsoon season. The ecologically vulnerable aquatic species contributed 20 $25 \%$ of the total catch and it is inferred that the estuary has a greater role in protecting these species.

Interpretation : Small scale gillnet fishery of the estuary is analysed and documented in this study. The seasonal patterns in fish species composition catch rate and catch value are essential requirements for designing fisheries management. The present study gives insights formulate fisheries management actions to monitor and protect the fisheries resources of the estuary to ensure sustainable fisheries.

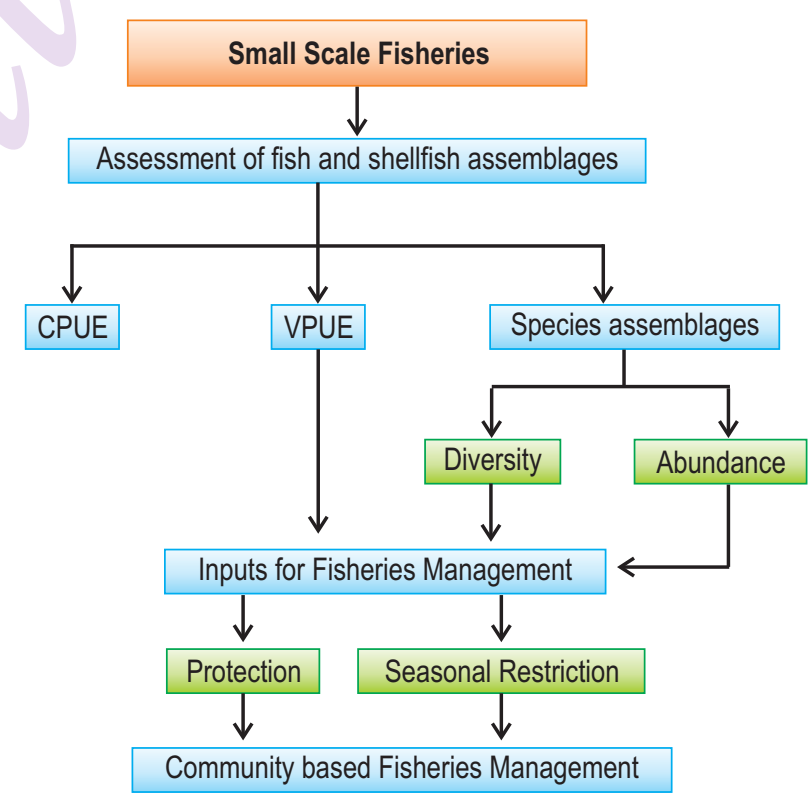




\section{Introduction}

In the tropical coastal ecosystems, estuaries play a major role inhabiting variety of aquatic organisms such as fish and crustaceans (Ansari et al., 1995; George et al., 2013; Sreekanth et al., 2015a). These assemblages of species that inhabit estuaries represent resident estuarine and marine migrant species (Baker and Sheppard, 2005; Franco et al., 2012; Rajesh et al., 2015). Thus, estuaries function as a significant nursery ground for several marine and coastal fish species (Dolbeth et al., 2011; Pasquaud et al., 2015), and these species congregate in this zone for reproduction, feeding and shelter. Most of these species have tolerance to the highly varying environmental conditions in the estuaries (Ansari et al., 1995; Barbone and Basset, 2010; Sreekanth et al., 2015a). The seasonal reversal of winds in the Arabian Sea termed as 'southwest monsoon', results in heavy precipitation along the west coast of India during June to September (Shamsan, 2008). This monsoon phenomenon causes seasonality in the coastal environment which is generally classified into three seasons, namely pre-monsoon (February-May), monsoon (June-September) and post-monsoon (October-January) seasons (Shamsan, 2008; Sreekanth et al., 2015a). Therefore, monsoon mediated environmental fluctuations in the coastal ecosystem are expected to affect the spawning and movement activities of aquatic species and thus, influences the diversity of fish species (Ansari et al., 1995; Sreekanth et al., 2015a; Sreekanth et al., 2016). These environmental fluctuations cause seasonal migrations of fish species like movement of young fish from deeper waters to estuarine regions and movement of mature adult fish to spawning grounds and thus bring out seasonal variations in the fish assemblages (Harrison and Whitfield, 2006; Costa et al., 2007; Barbone and Basset, 2010). Thus, it is obvious that the estuaries hold multispecies fisheries with seasonal changes in fish communities. Therefore to manage such fishery, assessment of structure and dynamics of fish community is an essential requirement.

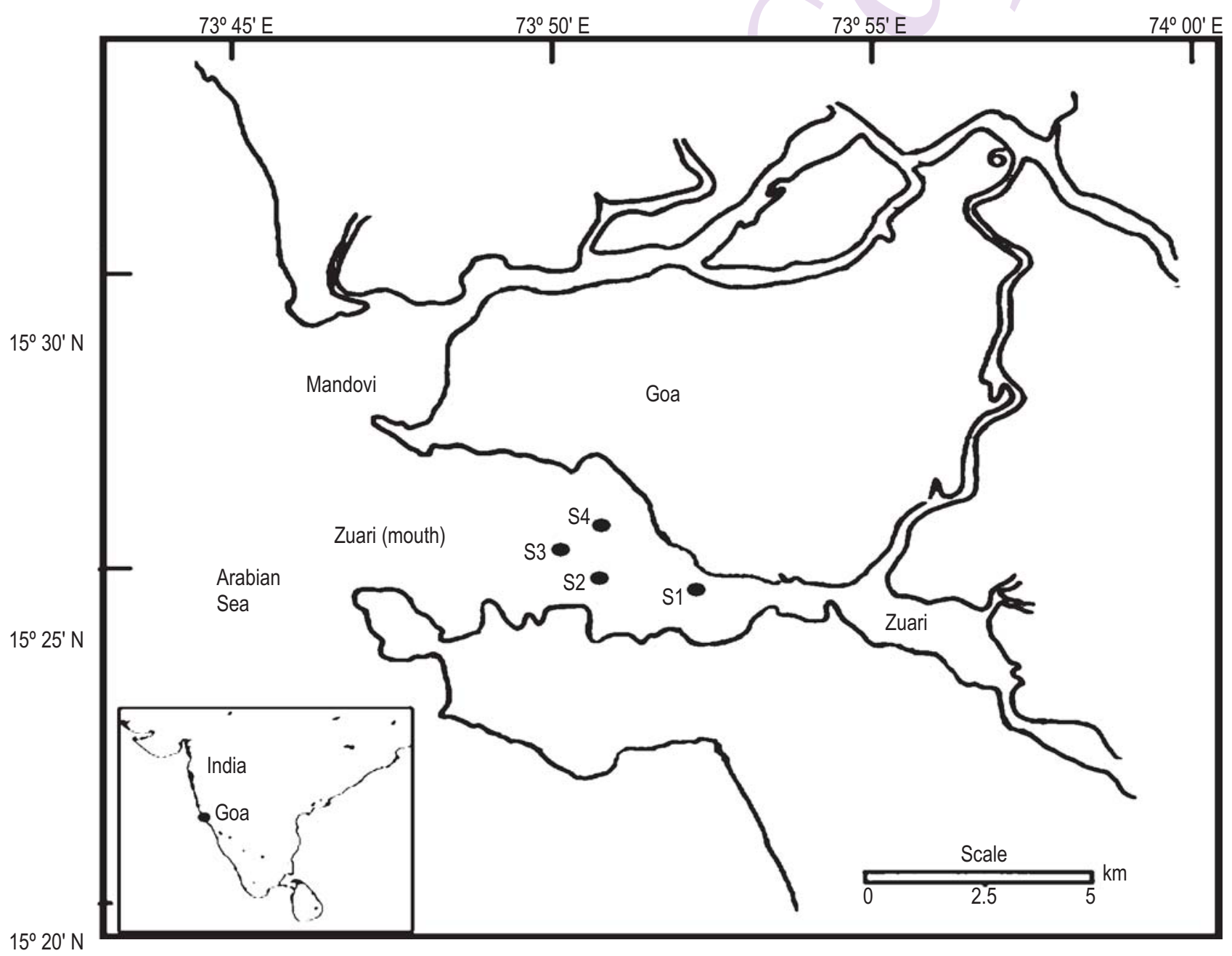

Fig. 1 : The experimental fishing sites represented as solid circles with labels from S1 to S4 in Zuari estuary 
With a total area of $39.9 \mathrm{~km}^{2}$, Zuari estuary in Goa is one of the major estuaries located along the southwest coast of India which connects to the Arabian Sea through Mormugao Bay (Fig. 1). The margins of Zuari estuary have dense mangrove vegetation filled with silt, clay and detritus that has been transported by riverine influx from upper reaches. The entire mudflats along with mangrove vegetation makes the region highly productive supporting large number of economically important species (Sreekanth et al., 2015a). This region receives maximum precipitation during the southwest monsoon accompanied by stormy weather, while quieter conditions prevail during rest of the year. The existence of typical tropical conditions characterized by high temperature, longer photoperiod and long flushing period are conducive to greater biological productivity and thus, greater species diversity in the estuary (Shirodkar et al., 2012). Reports reveal that the region is very important to a number of finfish and shellfish of commercial significance (Ansari et al., 1995; Sreekanth et al., 2015a; Sreekanth et al., 2015b). Small scale traditional fishery within this coastal zone is considered to be an activity in the northern stretches which will be significantly correlated to the finfish and shellfish diversity in this estuary (Sreekanth et al., 2015a).

The entire coastal zone has a bed of rocky patches (which makes it unsuitable for trawling) and hence, the gillnet fishery represent majority of the landed catch. The region holds fishing villages like Siridao, Cacra, Odxal, Bambolim and Nauxim which lands about 600-1000 tonnes of fish every year (Sreekanth et al., 2015b). Hence, a comprehensive assessment of this small scale fisheries is required in the estuary. The objective of the present study was to analyse seasonal patterns in fish species composition, catch rates and catch value in small scale fishery.

\section{Materials and Methods}

Study area and fishing operations: The present study is based on major fishing grounds in Zuari estuary, one of the major estuaries of Goa connecting to the Arabian Sea (Fig. 1). A total of 40 motorised boats (made of FRP or wood which use an out board motor (OBM) of less than $10 \mathrm{HP}$ for propulsion) and 30 nonmotorised boats (artisanal) were used in this estuary for gillnet fishing. Monofilament nylon surface and bottom set gillnets of 30$60 \mathrm{~mm}$ mesh size was commonly used in the estuary targeting mackerel, sardines, white sardine, mullets, white baits, moustached anchovy, mullets, silver bellies, carangids, croakers, cat fish, crabs and shrimps (Sreekanth et al., 2015b).

In-situ fishing operations were carried out on monthly basis to study the seasonal pattern in fish assemblages, catch rates (CPUE) and catch value (VPUE) from September, 2013 to August, 2015. Four locations commonly used for commercial gillnet operations were chosen for fishing experiments (Fig. 1). A total of 288 fishing operations with 4 operations in a day at each location were carried out in 72 fishing days, three each in a month and the day being selected randomly within each 10 days increment. Gillnets of $30 \mathrm{~mm}$ mesh size (minimum legal mesh size for gillnet) of $400 \mathrm{~m}$ length (commonly used by the fishermen) were used and operations were set to run for $2 \mathrm{hrs}$ at depth range of 3-5 $\mathrm{m}$ (Sreekanth et al., 2015a).

Fish species abundance and relative importance index (RII) : Fish and shellfish fauna collected during the study were identified to the family, genus and species levels. They were also classified on the basis of trophic levels and feeding preferences as planktivores, herbivores, carnivores and omnivores. Further, they were categorised based on their economic importance (major, minor and non-commercial). They were also grouped on the basis of ecological resilience and vulnerability (Froese and Pauly, 2000). The number and weight of each species (abundance) caught during each fishing trip was counted and recorded. The monthly abundance of species and weight of catch were calculated as cumulative values for three days randomly selected in that month. Further, the abundance and species catch data were used to calculate an index, relative importance index (RII) (De la Cruz-Aguero, 1994) which represents the most important species for the abundance (\% of individuals), catch weight (kg) and frequency (\% of samples). The catch weight and abundance of species was calculated as cumulative sum of average daily catch for 24 months (one representative value/ month). Similarly, the catch weight and abundance for species was calculated for various seasons.

Statistical models make assumptions about the probability distributions of species abundance in an ecosystem (Taylor et al., 1976). In the present study, four distribution models namely broken stick, geometric, log-series and log-normal models were used for comparing the species abundance between the seasons (May, 1975). These species abundance curves were generated using the 'PROC SGPLOT' procedure of SAS software (SAS Institute, 2012; Sreekanth et al., 2016).

Catch rates (CPUE) and Value rates (VPUE) : The catch per unit effort (CPUE) was designated as catch rate and estimated as catch $(\mathrm{kg})$ obtained for a fishing unit/day. The value per unit of effort (VPUE) was designated as the catch value (Rs.) for catch rate (CPUE). The VPUE was calculated by multiplying the month wise average price for fish catch with CPUE. The monthly average values of CPUE and VPUE were calculated from the catch data of fishing operations for three days randomly selected during that month.

Statistical analysis : To classify and determine the effects of season, the months were divided into three seasons premonsoon (February to May), monsoon (June-September) and post-monsoon (October to January) seasons. The data on species abundance, catch weight of species, CPUE and VPUE were pooled separately for fishing locations and seasons. The variables; abundance, CPUE and VPUE were transformed using the equation $\log (X+1)(' X '$ represents absolute value of the 
Table 1 : Values of Relative Importance Index for the most important species during study period

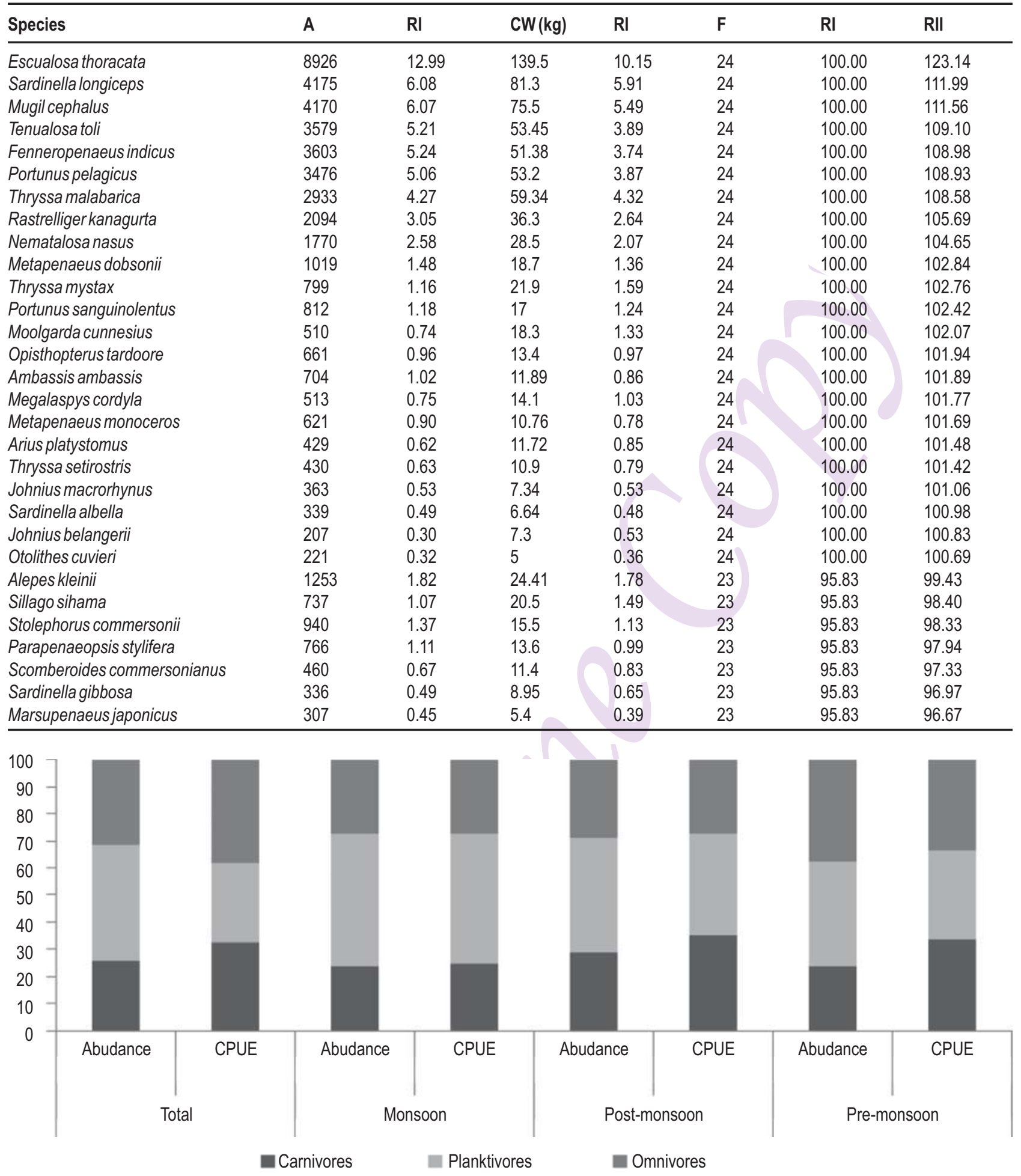

Fig. 2 : Percentage contribution of various feeding groups to abundance and CPUE for the entire sampling period and during different seasons

variable) and tested using two way ANOVA to determine whether they were significantly different between seasons and sites. Further, Tukey's HSD was used for multiple comparison of variables displaying significant difference for the effect site or season. All these analyses were carried out by SAS software (SAS Institute, 2012). 


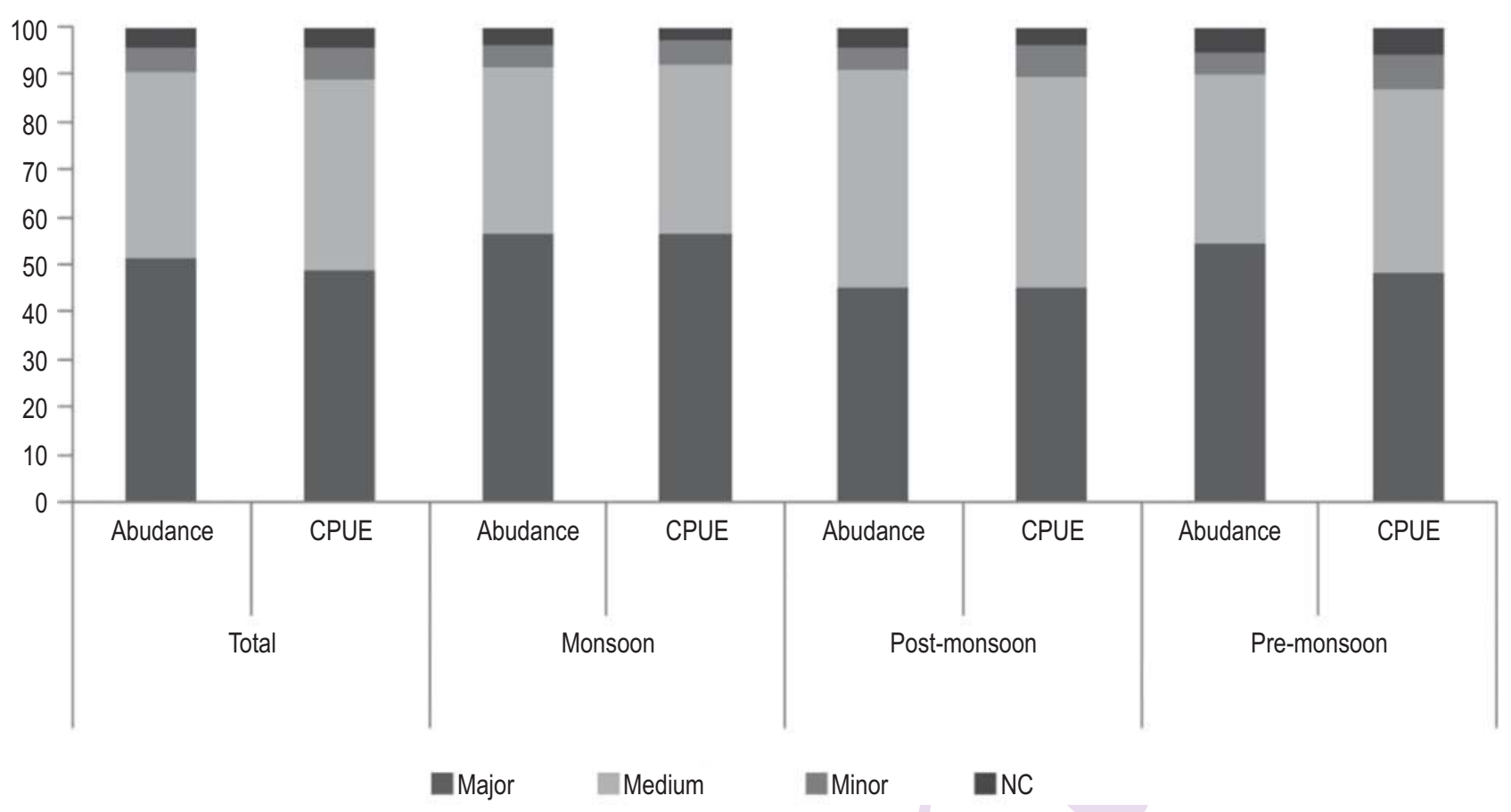

Fig. 3 : Percentage contribution of various groups based on fisheries importance to abundance and CPUE for the entire sampling period and during different seasons (NC is non-commercial)

Table 2 : ANOVA and post-hoc comparison results of abundance, CPUE and VPUE across sampling stations and seasons

\begin{tabular}{|c|c|c|c|c|c|c|c|c|c|}
\hline \multirow[t]{2}{*}{ Variable } & \multirow{2}{*}{ 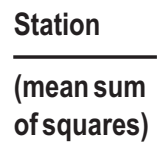 } & \multirow{2}{*}{$\begin{array}{l}\text { Season } \\
\text { (mean sum } \\
\text { of squares) }\end{array}$} & \multicolumn{3}{|c|}{ Station (Mean $\pm S E$ ) } & \multicolumn{2}{|c|}{ Season (Mean $\pm S E)$} & \multirow[b]{2}{*}{$\begin{array}{l}\text { Post-monsoon } \\
\left(96^{\#}\right)\end{array}$} & \multirow[b]{2}{*}{$\begin{array}{l}\text { Pre-monsoon } \\
\left(96^{\#}\right)\end{array}$} \\
\hline & & & $\mathrm{S} 1\left(72^{\#}\right)$ & $S 2\left(72^{\#}\right)$ & S3 $\left(72^{\#}\right)$ & S4 $\left(72^{\#}\right)$ & $\begin{array}{l}\text { Monsoon } \\
\left(96^{\#}\right)\end{array}$ & & \\
\hline Abundance & $0.26^{\mathrm{NS}}$ & $1.81^{*}$ & $6.32 \pm 0.14^{a}$ & $6.24 \pm 0.22^{\mathrm{a}}$ & $6.27 \pm 0.16^{a}$ & $6.41 \pm^{a}$ & $6.71 \pm 0.11^{c}$ & $7.52 \pm 0.13^{\mathrm{a}}$ & $7.11 \pm 0.18^{b}$ \\
\hline CPUE & $0.51^{\mathrm{NS}}$ & $2.15^{*}$ & $3.12 \pm 0.11^{\mathrm{a}}$ & $3.18 \pm 0.14^{a}$ & $3.15 \pm 0.15^{\mathrm{a}}$ & $3.21 \pm 0.20^{\mathrm{a}}$ & $2.62 \pm 0.14^{b}$ & $3.73 \pm 0.09^{a}$ & $3.31 \pm 0.16^{b}$ \\
\hline VPUE & $0.38^{\mathrm{NS}}$ & $1.89^{*}$ & $6.77 \pm 0.23^{\mathrm{a}}$ & $6.85 \pm 0.19^{\mathrm{a}}$ & $6.76 \pm 0.22^{\mathrm{a}}$ & $6.80 \pm 0.26^{\mathrm{a}}$ & $6.50 \pm 0.18^{c}$ & $7.75 \pm 0.16^{\mathrm{a}}$ & $7.20 \pm 0.21^{\mathrm{b}}$ \\
\hline
\end{tabular}

The superscript for the mean values indicates the grouping obtained in the post-hoc comparison and the same superscript shows no significant difference for the variables between seasons and stations, ${ }^{\#}$ indicates the number of samplings, "significant at $5 \%$ level, ${ }^{\mathrm{NS}}$ not significant, All variables were significantly different between seasons with a $\mathrm{R}$-square value greater than 0.6

\section{Results and Discussion}

A total of 68,715 organisms weighing $13980.4 \mathrm{~kg}$ were caught in which 213 aquatic species from 76 families were included. 30 species contributed to about $69 \%$ of total abundance, $61 \%$ of weight and $95 \%$ of frequency in the catch (Table 1). The most important species based on RII were Escualosa thoracata, Sardinella longiceps, Mugil cephalus, Tenualosa toli, Fenneropenaues indicus, Portunus pelagicus, Thryssa malabarica, Rastrelliger kanagurta, Nematalosa nasus and Metapenaeus dobsonii (Table 1). On the basis of numerical abundance, planktivores and omnivores were the major groups followed by carnivores (Fig. 2). Based on catch weight, omnivores and carnivores were the most abundant groups followed by planktivores (Fig. 2). On the basis of numerical abundance and catch weight, major and medium fisheries groups represented bulk of the fish catch (Fig. 3). Based on the ecological vulnerability, low and moderate categories dominated over others on the basis of numerical abundance and catch weight (Fig. 4).

During monsoon, a total of 18,505 organisms weighing $3000.5 \mathrm{~kg}$ were caught in which 160 species from 45 families were included. Thirty species contributed about $74 \%$ of abundance, $71 \%$ of weight and $85 \%$ frequency in the catch. The most important species based on RII were E. thoracata, $S$. longiceps, M. cephalus, F. indicus, $R$. kanagurta, T. malabarica, $T$. toli, P. pelagicus, N. nasus and Thryssa mystax. Planktivores and omnivores were the major groups (Fig. 2). On the basis of fisheries importance, major and medium groups dominated over other groups (Fig. 3). On the basis of ecological vulnerability, low and moderate groups were abundant (Fig. 4). 


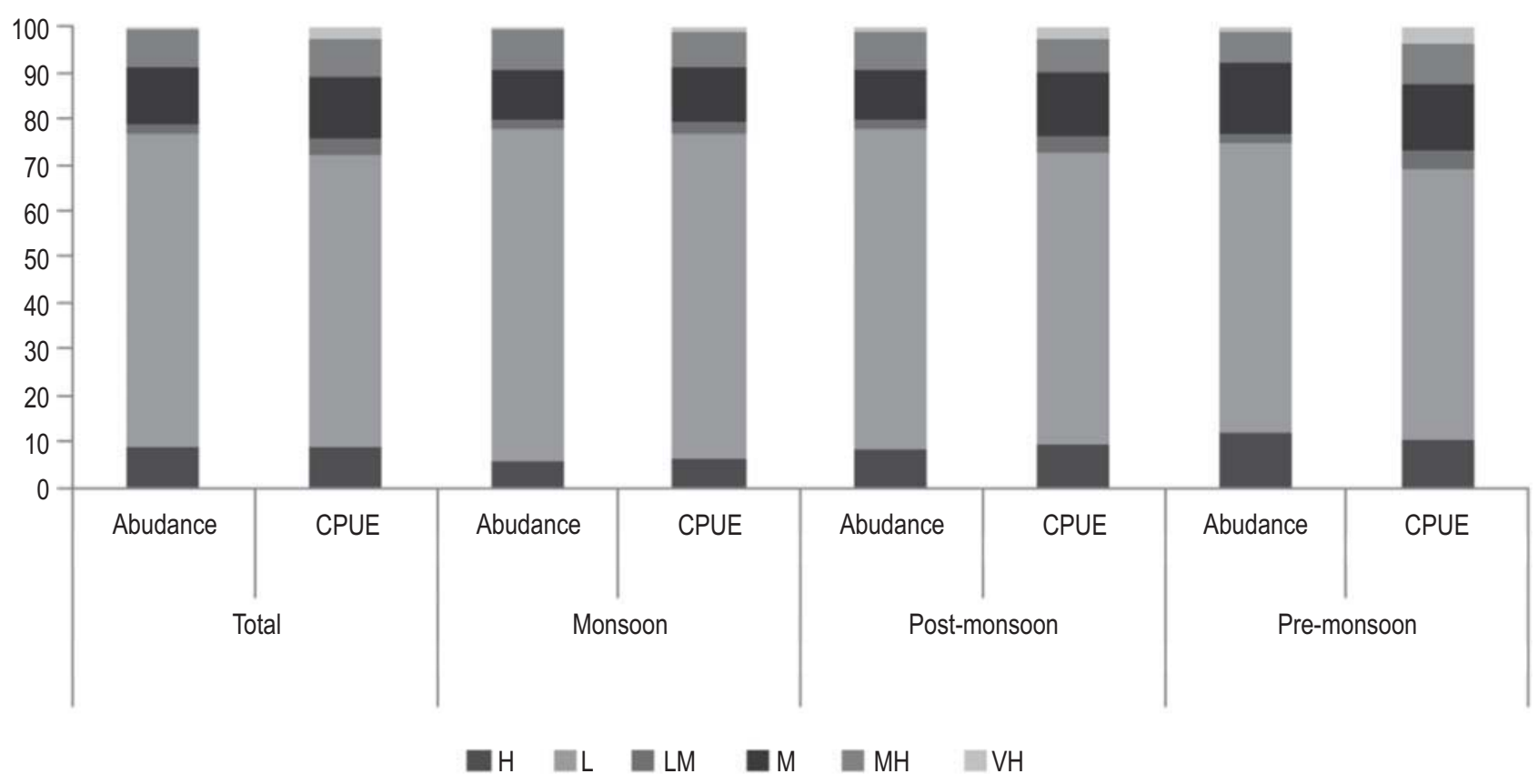

Fig. 4 : Percentage contribution of various groups based on ecological vulnerability to abundance and CPUE for the entire sampling period and during different seasons (H-high, L-low, LM-low to moderate, M-moderate, MH-moderate to high, VH-very high)

Table 3: Species abundance fitted for distribution models

\begin{tabular}{|c|c|c|c|c|c|c|}
\hline \multirow[t]{2}{*}{ Model } & \multicolumn{2}{|c|}{ Monsoon } & \multicolumn{2}{|c|}{ Post-monsoon } & \multicolumn{2}{|c|}{ Pre-monsoon } \\
\hline & Parameters & Chi-square & Parameters & Chi-square & Parameters & Chi-square \\
\hline Geometric & $k=0.0543$ & $9894.2^{* *}$ & $k=0.04148$ & $784.5^{\mathrm{NS}}$ & $k=0.0426$ & $685.34^{\mathrm{NS}}$ \\
\hline Log-series & $\begin{array}{l}\text { alpha=15.31, } \\
X=0.986\end{array}$ & $95.21^{\mathrm{NS}}$ & $\begin{array}{l}\text { alpha=16.71, } \\
X=0.975\end{array}$ & $34.28^{\mathrm{NS}}$ & $\begin{array}{l}\text { alpha=17.42, } \\
X=0.994\end{array}$ & $42.31^{\text {NS }}$ \\
\hline Broken-stick & & $96.2^{\mathrm{NS}}$ & & $363.3^{\mathrm{NS}}$ & & $268.4^{\mathrm{NS}}$ \\
\hline Log-Normal & $\begin{array}{l}\text { Mean }=1.498 \\
\text { Var=0.625 }\end{array}$ & $14.12^{\mathrm{NS}}$ & $\begin{array}{l}\text { Mean }=1.865, \\
\text { Var }=0.605\end{array}$ & $3.75^{\prime \prime}$ & $\begin{array}{l}\text { Mean }=1.792 \\
\text { Var=0.616 }\end{array}$ & $2.42^{*}$ \\
\hline
\end{tabular}

"fitted with the model, ${ }^{\mathrm{NS}}$ not fitted with the model, The null hypothesis assumed there is no significant difference between the distribution model and the observed species abundances

During post-monsoon, a total of 28,610 organisms weighing $6150.4 \mathrm{~kg}$ were caught in which 181 species from 62 families were included. Among these, thirty species contributed about $78 \%$ of abundance, $70 \%$ of weight and $100 \%$ frequency in the catch. The most important species based on RII were $E$. thoracata, Leiognathus brevirostris, T. toli, M. cephalus, T. malabarica, P. pelagicus, S. longiceps, F. indicus, N. nasus and $R$. kanagurta. Planktivores and carnivores were the major groups (Fig. 2). On the basis of fisheries importance, major and medium groups were dominated over others (Fig. 3). On the basis of ecological vulnerability, low and moderate groups were abundant (Fig. 4).

During pre-monsoon, a total of 21,600 organisms weighing $4820.5 \mathrm{~kg}$ were caught in which 191 species from 70 families were were included. Thirty species contributed about $77 \%$ of abundance, $69 \%$ of weight and $100 \%$ frequency in the catch. The most important species based on RII were $E$. thoracata, S. longiceps, P. pelagicus, F. indicus, M. cephalus, T. malabarica, L. brevirostris, T. toli, R. kanagurta and M. dobsonii. On the basis of numerical abundance, planktivores and omnivores were the major groups (Fig. 2). However, carnivores were dominant on the basis of catch weight. On the basis of fisheries importance, major and medium groups were dominated over others (Fig. 3). On the basis of ecological vulnerability, low and moderate groups dominated over other groups (Fig. 4).

Species abundance in monsoon fitted to a geometric series while for other seasons, it followed a log-normal distribution. For this, the table of chi-square test and the 

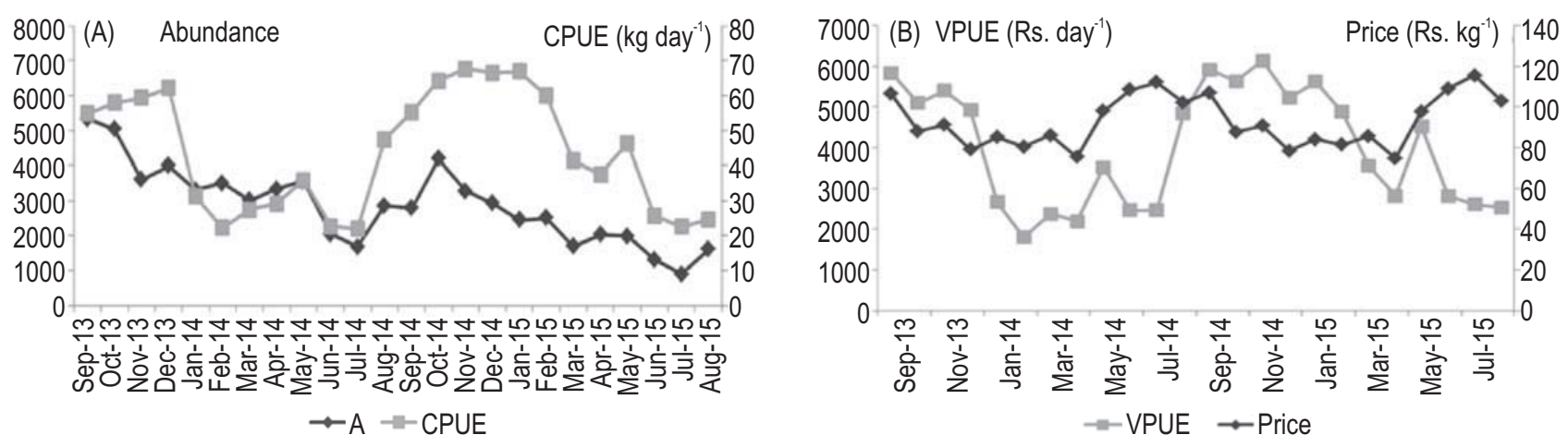

Fig. 5 : Monthly variation of fishery related variables in gillnet fishery of Zuari estuary (A- monthly abundance and average CPUE, B-average VPUE and average price)

abudance plot were took from the recently published research paper (Sreekanth et al., 2016). The abundance, CPUE and VPUE demonstrated great variations and in a day's fishing operation and an average of 2870 organisms of $43.8 \mathrm{~kg}$ were caught with a VPUE of Rs. 3995.50. The abundance, CPUE and VPUE were significantly less during monsoon and maximum during postmonsoon (Table 2, Fig. 5). However, there were no significant differences in the abundance, CPUE and VPUE between sites of fishing (Table 2).

On the basis of RII, the first six species were analysed for their variations in abundance, CPUE and VPUE. For individual species, the variation of abundance and CPUE demonstrated great similarity (Fig. 7) and each species showed seasonality in abundance and CPUE. The abundance and CPUE of $E$. thoracta and $M$. cephalus were maximum in post-monsoon season (Fig. 7). At the same time, S. longiceps demonstrated higher abundance and CPUE in monsoon and pre-monsoon (Fig. 6). The crustacean species, $F$. indicus and $P$. pelagicus were maximum during pre-monsoon (Fig. 7).

The total number of species observed in this study was comparatively higher (213 species) compared to earlier reports (Whitfield, 1999; Rojo-Vazquez et al., 2008; Sreekanth et al., 2015a). The presence of diverse structural habitats with sandy, muddy and rocky patches in the estuary might have contributed to the huge diversity of aquatic species in the ecosystem (Sreekanth et al., 2015a). RIl has identified 30 important aquatic species which contribute significantly to the coastal fishery of Zuari and it implies that a few species contributes to the estuarine fishery (Rojo-Vazquez et al., 2008; Pasquaud et al., 2015; Sreekanth et al., 2015a).

A general consensus is that low species diversity in monsoon may be attributed to lowering of salinity due to increased freshwater discharge from rivers (Costa et al., 2007; Barbone and Basset, 2010; Sreekanth et al., 2015a). Zuari estuary gets a large fresh water influx $\left(9 \mathrm{~km}^{3}\right)$ from the upper reaches in monsoon (Sreekanth et al., 2016) and this causes seasonal fluctuation in salinity and temperature. Thus, the seasonal fluctuations in the species composition may be attributed to the distinct seasonal patterns in salinity and temperature (Harrison and Whitfield, 2006; Rojo-Vazquez et al., 2008; Rajesh et al., 2015; Sreekanth et al., 2015a; Sreekanth et al., 2016). The fish species composition exhibited high diversity and abundance in post-monsoon and premonsoon while seasonal species dominated in monsoon. This may be attributed to seasonal migrations of species for breeding, larval development and feeding, as a result of variations in salinity and temperature (Sreekanth et al., 2015a; Sreekanth et al., 2016).

Tropical estuaries are considered as primary nursery grounds for coastal aquatic species (Jaureguizar et al., 2004; Dolbeth et al., 2011; Sreekanth et al., 2015a; Sreekanth et al., 2016). Greater species richness and diversity noticed in this study suggest that the estuary provides unique habitat characteristics, which may not be found on offshore and upstream ecosystems. The fish communities in the estuary represent all different trophic levels in the food chain (Elliott et al., 2007; Harrison and Whitfield, 2012; Sreekanth et al., 2015a). The estuary has provided shelter to 126 ecologically vulnerable species (Musick, 1999; Cheung et al., 2005) and species of fisheries importance were abundant in the estuary similar to other estuarine counterparts (Jaureguizar et al., 2004; Cabral et al., 2012; Franco et al., 2012; Sreekanth et al., 2015a).

Zuari estuary is subjected to active fishing using traditional and motorised boats similar to other coastal ecosystems (Rueda and Defeo, 2003; Shamsan, 2008; Sreekanth et al., 2015a). The abundance of larval, juvenile and adult fish populations in post-monsoon and pre-monsoon seasons attracts the fishermen for intensive fishing in this estuary (Sreekanth et al., 2015a). In this study, seasonal patterns in fish communities in terms of numerical abundance, CPUE and VPUE were highlighted in Zuari estuary, which is a pre-requisite to manage the fishery. A suitable practical fisheries management 

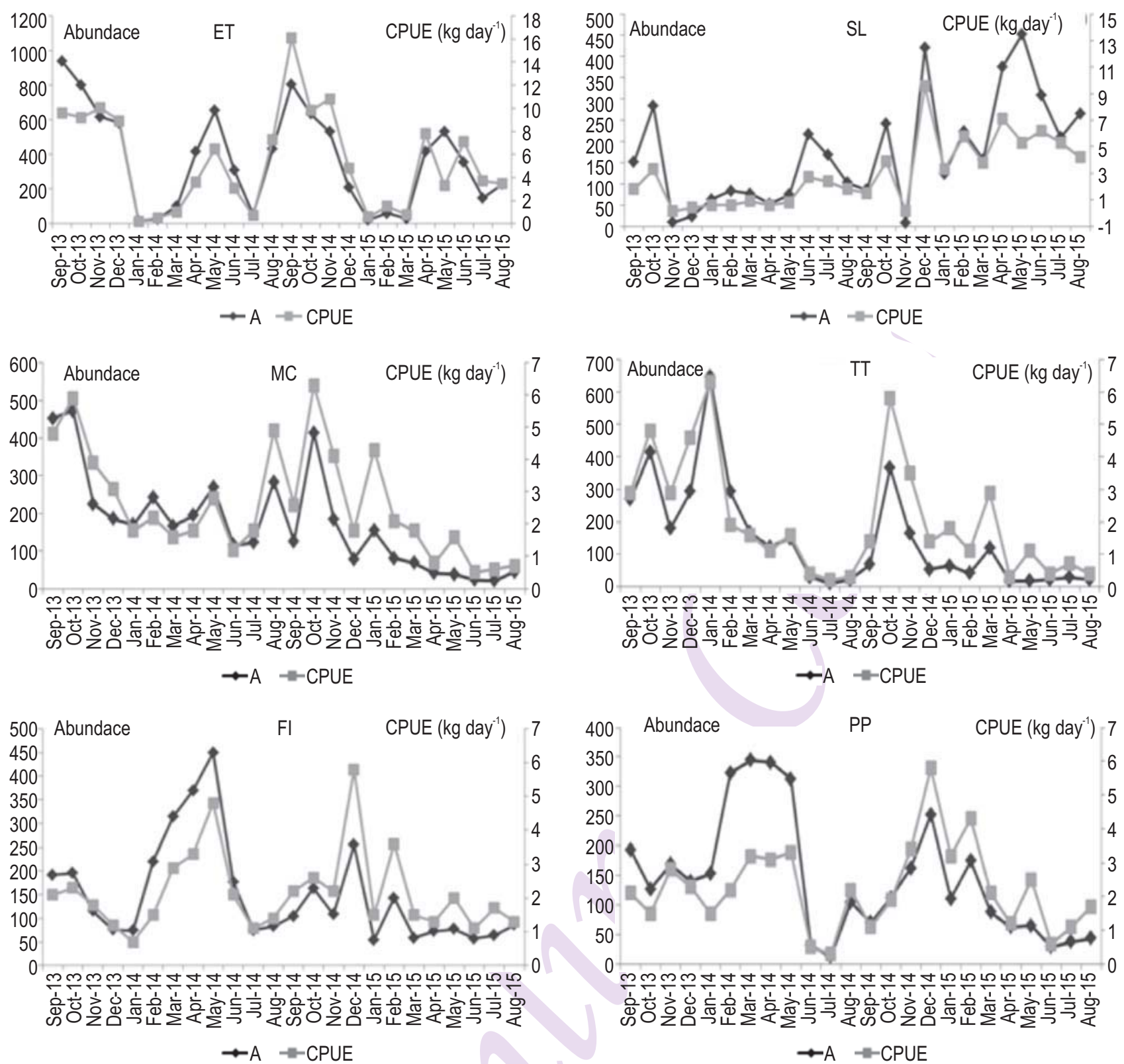

Fig. 6 : Monthly variation of abundance and average CPUE for six important species in gillnet fishery of Zuari estuary (ET- Escualosa thoracata, SLSardinella longiceps, MC- Mugil cephalus, TT- Tenualosa toli, FI-Fenneropenaeus indicus, PP- Portunus pelagicus)

intervention like a community based fisheries management with proper monitoring of fish catch and illegal intrusions, reporting systems, fishing holidays, seasonal and regional closures can be a practical solution to sustainably manage the fisheries resources in the estuary.

\section{Acknowledgments}

The authors are grateful to the Director of Fisheries, Dr. Shamila Monteiro, Superintendent of Fisheries, Dr. Hrishikesh Pawar and other staff of the Department of Fisheries for their support and guidance for the present study. The authors express their heartfelt thanks to research scholars (Department of Fisheries and Goa University) and fishermen along the Siridao coast for their kind co-operation with the fishing experiments, in particular, Mr. Sanjay Perera, (Head of Tiswadi Fishermen Association, North Goa) who provided assistance in site selection and sampling.

\section{References}

Ansari, Z.A., A. Chatterji, B.S. Ingole, R.A. Sreepada, C.U. Rivonkar and A.H. Parulekar: Community structure and seasonal variation of an inshore demersal fish community at Goa, West Coast of India. 
Estuar. Coast. Shelf Sci., 41, 593-610 (1995).

Baker, R. and R. Sheppard: Fisheries resources of Cleveland Bay (Townsville). QDPIF Information Series, Q105021 (2005).

Barbone, E. and A. Basset: Hydrological constraints to macrobenthic fauna biodiversity in transitional waters ecosystems. Rendiconti. Lincei., 21, 301-314 (2010).

Cabral, H.N., V.F. Fonseca, R. Gamito, C.I. Gonçalves, J.L. Costa, K. Erzini, J. Gonçalves, J. Martins, L. Leite, J.P. Andrade and S. Ramos: Ecological quality assessment of transitional waters based on fish assemblages in Portuguese estuaries: The Estuarine Fish Assessment Index (EFAI). Ecol. Indic., 19, 144-153 (2012).

Cheung, W.W.L., T.J. Pitcher and D. Pauly: A fuzzy logic expert system to estimate intrinsic extinction vulnerabilities of marine fishes to fishing. Biol. Cons., 124, 97-111 (2005).

Costa, M.J., R. Vasconcelos, J.L. Costa and H.N. Cabral: River flow influence on the fish community of the Tagus estuary (Portugal). Hydrobiologia, 587, 113-123 (2007).

De la Cruz-Aguero, G.: ANACOM. Sistema para el analisis de Comunidades. Manual del usuario, La Paz., B. C. S., Mexico (1994).

Dolbeth, M., F. Martinho, V. Freitas, S. Costa-Dias, J. Campos and M.A. Pardal: Multi-year comparisons of fish recruitment, growth and production in two drought-affected Iberian estuaries. Mar. FreshwaterRes., 61, 1399-1415(2011).

Elliott, M., A.K. Whitfield, I.C. Potter, S.J. Blaber, D.P. Cyrus, F.G. Nordlie and T.D. Harrison: The guild approach to categorizing estuarine fish assemblages: a global review. Fish Fish., 8, 241-268 (2007).

Franco, A., A. Pérez-Ruzafa, H. Drouineau, P. Franzoi, E.T. Koutrakis, M. Lepage, D. Verdiell-Cubedo, M. Bouchoucha, A. López-Capel, F. Riccato and A. Sapounidis: Assessment of fish assemblages in coastal lagoon habitats: Effect of sampling method. Estuar. Coast. Shelf Sci., 112, 115-125 (2012).

Froese, R. and D. Pauly: FishBase 2000: Cocepts, design and data sources. ICLARM, Laguna, Philippines (2000).

George, G., D.V. Desai, C.A. Gaonkar, V.M. Aboobacker, P. Vethamony and A.C. Anil: Barnacle larval transport in the Mandovi- Zuari estuarine system, central west coast of India. J. Oceanogr., 69, 451-466 (2013).

Harrison, T.D. and A.K. Whitfield: Fish trophic structure in estuaries, with particular emphasis on estuarine typology and zoogeography. J. Fish Biol., 81, 2005-2029 (2012).

Harrison, T.D. and A.K. Whitfield: Temperature and salinity as primary determinants influencing the biogeography of fishes in South African estuaries. Estuar. Coast. Shelf Sci., 66, 335-345(2006).

Jaureguizar, A.J., R. Menni, R. Guerrero and C. Lasta: Environmental factors structuring fish communities of the Rio de la Plata estuary. Fish. Res., 66, 195-211 (2004).

May, R.M.: Patterns of species abundance and diversity. In: Ecology and evolution of communities (Eds.: M.L. Cody and J.M. Diamond). Belknap Press, Cambridge. pp. 81-120 (1975).

Musick, J.A.: Criteria to define extinction risk in marine fishes. Fisheries, 24, 6-14 (1999).

Pasquaud, S., R.P. Vasconcelos, S. França, S. Henriques, M.J. Costa and H. Cabral: Worldwide patterns of fish biodiversity in estuaries: Effect of global vs. local factors. Estuar. Coast. Shelf Sci., 154, 122-128 (2015).

Rajesh, K.M., S. Thomas, A.P. Dineshbabu, R. Prathibha, B. Sridhara and G.D. Nataraja: Seasonal abundance and composition of finfish and shellfish seeds in mangroves of Gangoli estuary, off south-west coast of India. J. Env. Biol., 36, 1367-1371 (2015).

Rojo-Vazquez, J.A., C. Quinonez-Velazquez, H.A. Echavarria-Heras, G. Lucano-Ramirez, E. Godinez-Dominguez, S. Ruiz-Ramirez, V.H. Galvan-Pina and O. Sosa-Nishizaki: The fish species composition and variation of catch from the small scale gillnet fishery before, during and after the 1997-1998 ENSO event, Central Mexican Pacific. Rev. Bio. Trop., 56, 133-152 (2008).

Rueda, M. and O. Defeo: A bioeconomic multispecies analysis of an estuarine smallscale fishery: Spatial structure of biovalue. ICES J. Mar. Sci., 60, 721-732 (2003).

SAS Institute: SAS/STAT. User's Guide, Version 9.2. SAS Institute, Cary, NC, $4^{\text {th }}$ Edn. Vol. 1 (2012).

Shirodkar, P.V., M. Deepthi, P. Vethamony, A.M. Mesquita, U.K. Pradhan, M.T. Babu, X.N. Verlecar and S.R. Haldankar: Tide dependent seasonal changes in water quality and assimilative capacity of anthropogenically influenced Mormugao harbour water. Indian J. Geo-Mar. Sci., 41, 314-330 (2012).

Sreekanth, G.B., N. Manju Lekshmi and N.P. Singh: Fisheries profile of Zuari estuary. Int. J. Fish. Aquat. Stud., 3, 24-34 (2015b).

Sreekanth, G.B., N. Manju Lekshmi and N.P. Singh: Temporal patterns in fish community structure: environmental perturbations from a wellmixed tropical estuary. PNAS-SEC-B Bio. Sci., DOI: 10.1007/s 40011-015-0581-2) (2015a).

Sreekanth, G.B., N. Manju Lekshmi, S.K. Chakraborty, A.K. Jaiswar, P.U. Zacharia, V.R. Renjith, N.P. Singh and D.G. Pazhayamadom: Effect of monsoon on coastal fish diversity of Goa: an example from gill net fishery. Indian J. Fish., 63, 8-18 (2016).

Taylor, L.R., R.A. Kempton and I.P. Woiwod: Diversity statistics and logseries model. J. Anim. Ecol., 45, 255-272(1976).

Whitfield, A.K.: Ichthyofaunal assemblages in estuaries: a South African case study. Rev. Fish Biol. Fisher., 9, 151-186 (1999). 